\title{
The Wonderful Multifunctional Nucleolus of Hepatic Cell
}

\author{
Asomidin Sadriddinov, Kambarali Cheraliev, Nilufar Isaeva and Oblokul Murotov \\ Tashkent Pediatric Medical Institute, Tashkent 100140, Uzbekistan
}

\begin{abstract}
At research the liver of experimental animals: rabbits and rats the authors marked the phenomenon of nucleolus' going out from nucleus, and, it's conversion into new nucleus. At injection H3-timidin the nucleolus' going out and simultaneously DNA synthesis in separated complex were observed. It was determined the stimulation into new nucleus at introduction the new anti-inflammatory drug. The preliminary taken new data demand of additional confirming studies.
\end{abstract}

Key words: Morphology, liver, hepatocytes, binuclears, nucleolonuclear transformation.

\section{Introduction}

Recent years, along with the classic function of ribosome biogenesis many researchers showed nucleolus participation in cell cycle regulation, cell's proliferation, it's change under stressful conditions, tumor processes, viral damages, natural death of cells, in formation of bi- and polynuclears, aging of body, and, even at some human pathology Werner syndrome, Diamond-Blackton anemia, Treacher Collins syndrome, Rothmund-Thomson syndrome, etc. [1-7]. At study the nucleus structure of liver cells in rabbits, it was also revealed the considerable variability of form, quantity, and localization of nucleolus, and in some cases, it's going out from the nucleus to the cytoplasm with following change into the new structure. In present work, the data on participation of the nucleolus in formation process of bi-or and polynuclears due to nucleolonuclear transformation, are given.

\section{Materials and Methods}

The material is a liver of pubertal rabbits $(n=36)$ of both sexes weight 2.5-3.0 kg, being kept in usual conditions of vivarium. With observation ethical norms under light anesthesia the animals were killed by decapitation. Pieces of liver tissue for histological researches after fixation and processing were poured in

Corresponding author: Sadriddinov Asomidin Fayazovich, M.D., research area: histology, morphology, hepatology, gastroenterology. E-mail asom_sad_23@mail.ru. paraffin. For the light-optical researches the sections were stained with hematoxylin-eosin, and then were analyzed under immersion objective (x 100) of microscope model N-800 M.

Methodical ways, providing nucleolus' going out, and it's conversion into new nucleus, and, it's connection with cellular rejuvenation showed, that at light optical study some part of skepticism in authorizing of given phenomenon is left, and, so more exact methodical ways, proving nucleolus' going out from the nucleus, and, its conversion into new nucleus. In connection with it, it was decided to introduce the radioactive isotope first of all the including cellular nucleus, and, then, being taken out to cytoplasm, and being revealed in histological specimens in different periods after introduction. But we noticed that the nucleolus went, according to data of light optical studies, and, the part of doubts is quite small here, if DNA is really main problem of present discussion. Therefore, the isotope, being included in DNA marked N3-timidin, was chosen, and, it was introduced in dose $0.05 \mathrm{mkK} / \mathrm{gr}$ introabdominally for 6 days to mongrel rats with mass from 160 to $180.0 \mathrm{gr}$ the animal were kept in usual condition of vivarium, and, they were killed in 2, 30 or 90 days after entering isotope.

The proof universality of given phenomenon and participation of nucleolus in restoration processes in experiment showed, that, in order to determine if given phenomenon exist not only in rabbits but at other 
mammals, we chose wide used laboratory animal white mongrel rats, and, as experiment $25 \%$ liver resection (left lateral lobe of liver). The pubertal animals with mass from 180 to 200.0 gr under easy ethaminal narcosis, were undergone to laparotomy, and, liver resection was carried out by general method. Then the animals were killed in terms 3, 7, 15 and 30 days after operation. The liver pieces were treated with the above mentioned ways, and histological preparations both from control intact animals and, being operated experimental ones, were analyzed on the above mentioned microscope, gradually increasing label's number above the nucleolus. We had the task to reveal if the nucleolus participates in process of reparative regeneration at liver pathology. For solving this question we made up hepatitis modeling of chronic poisoning of liver with hepatropic poison heliotrin. The experimental animals were also white mongrel rats with body mass from 160 to 180 gr. The poisoning was carried out by H.Y. Karimov's scheme (1979). For 6 weeks the animals were intra- abdominally introduced heliotrin in dose $0.05 \mathrm{mg} / \mathrm{gr}$.

Practical significance of given phenomenon showed, that, till now, it was considered, that organs' regeneration, including liver, was provided with cellular division, compensatory hypertrophy, multinuclearity and polyploidy of cells.

\section{Results}

The results of taken studies showed, that there are usually from one to four nucleoli in hepatocytes, and, they have no strict definite localization in karyoplasm. At morphological analysis it was determined, that they can go out from the nucleus and turn into new nucleus, and, the cells become bi-or polynuclear hepatocytes (Fig. 1). The going out takes place in large uninuclear cells. Before going out one of the nucleolus becomes large in size, and, moves nearer to nuclear membrane then, such nucleolus penetrating it, goes out to cytoplasm of hepatocyte. It should be marked, that before going out from the nucleus the nucleoli have uneven shapes, and, after going out to cytoplasm, they obtain even contours with very dense matrix. Obdaining even round shape by the nucleolus is obviously connected with covering by the nuclear membrane. The going out "free" nucleolus is gradually increased in volume at cytoplasm, and, after original internal reconstructions it reaches the size of maternal nucleus, and, the nucleoplasm became considerably clear, and at first there appears the small one, then the second small dense body the future nucleoli. The internal reconstruction of nucleolus is evidently connected with untwisting polynucleotid chains both RNA and DNA, being enough spiralized before going out to cytoplasm. At the end from the little separated nucleolus the large spherical formation the new nucleus is formed, and, it is located near the old maternal one. It should be paid attention that in cytoplasm. At the end from the little separated nucleolus the large spherical formation the new nucleus is formed, and, it is located near the old maternal one. It should be paid attention that in rare cases from one nucleus two nucleoli are separated at once or from binuclear hepatocytes also two nucleolus occur, those are gradually turned out into new nuclei and the multinuclear (three or four nuclear) cells. The principal question in this process is possibility of formation the new cell with participation of separation nucleolus to cytoplasm. In favour of such possibility shows the appearance of free nucleolus in the center of cytoplasm without maternal nucleus, and, also the clear imitation of given cell from the surroundings (Fig. 2).

\section{Methodical Ways, Providing Nucleolus' Going Out, and Its Conversion into New Nucleus, and, Its Connection with Cellular Rejuvenation}

The results of autoradiographic studies showed that maximum including label was marked in 2 days of the experiment. At that, the labeled ones are turned out many hepatocytes with some predominance of cells with periportal zones. But, on the whole the number of labels in cells is some varied, that is connected with 

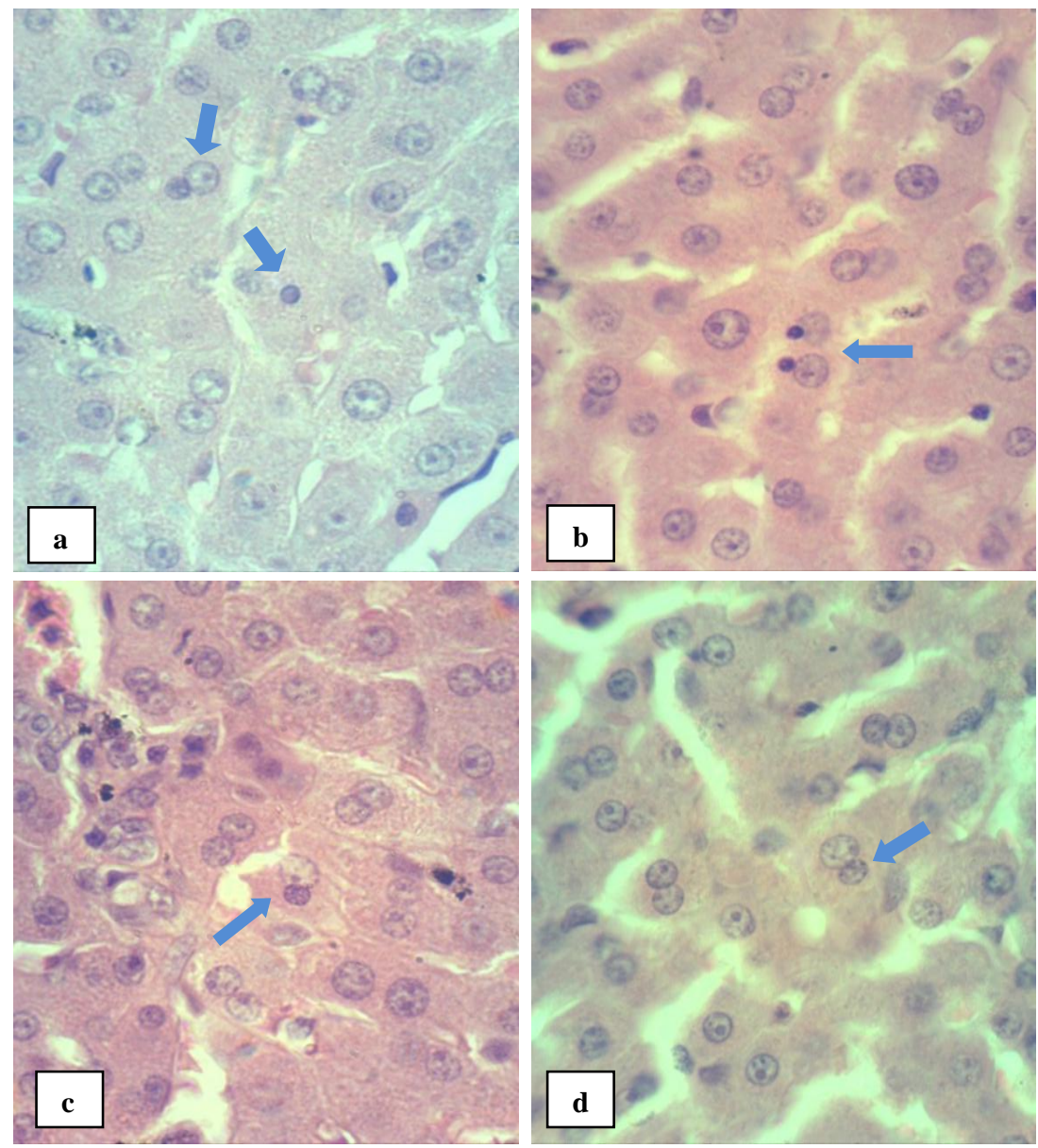

Fig. 1 Rabbit's liver. Colouring with hematoxilin-eosin. Immersion x 100 (oc.15. ob. 100).

$\mathrm{a}, \mathrm{b}$-Increase of nucleolus and synchronous going out of two nucleoli. c, $\mathrm{d}$-Different stages of nucleolonuclear transformation.

their presence in different periods of cellular cycle. The cells being in $\mathrm{S}$ period have maximum number of labels from 40 to 50 ones. In other cells the number of labels is more less. In 30 days of experiment the number of labels is considerably reduced. It takes place not only dilution of label on the unit of area, but many cells are deprived the labels, composing averagely from 20 to 30 labels. It should be marked, if many cells have the single grain of label, but only in some cells the number of labels is almost not changed, they have the same number of labels as at the beginning terms of isotope introduction. At searching cells with going out nucleolus, we could find out such picture, when the main nucleus has enough number of labels, and, with the help of thin isthmus it is connected with the going out nucleolus, also, having the label of isotope, but with little amount of it. The given micropictures prove visually the possibility formation the new nucleus on the account of nucleolus' going out, and, also with keeping small amount of DNA in it (Fig. 3).

At careful analysis of label's content in 30 and 90 days it was determined, that labels in many cells are fully disappeared, and, they are kept in some big nucleoli and, also, in small amount of nucleoli of different size, where the grains of labels are found out. There are occurs cells with little nucleoli, apparently, going out nucleoli, in karyoplasm of those gradually increase the labels' content on the way of enlargement of increasing their volume. These data show to possibility of DNA synthesis in just separated nucleoli. Except that, as it was above mentioned, the single cells have the same number of labels, as on the 2 nd day, i.e. 


\section{Fig. 2 Rat's liver.}
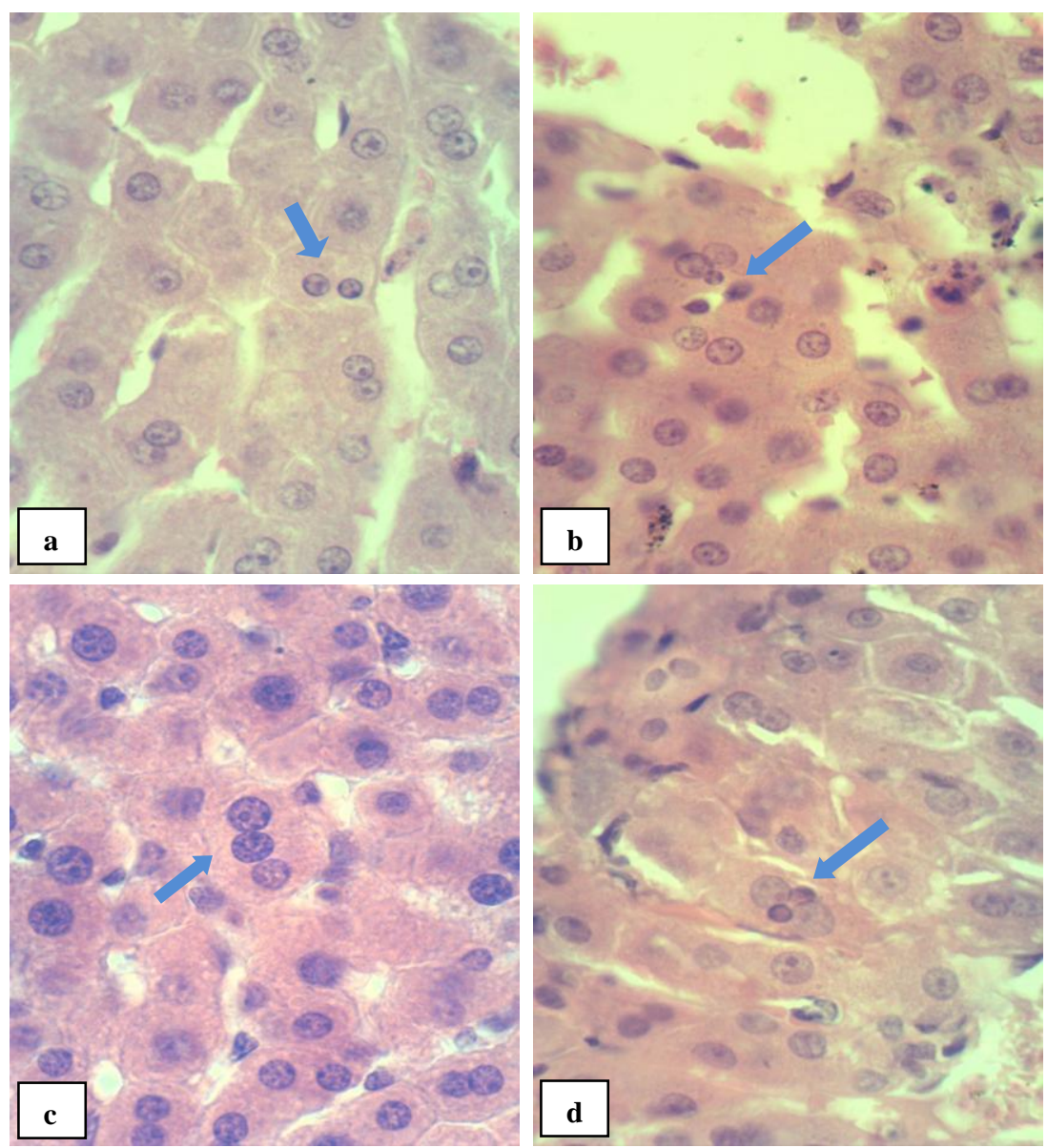

$\mathrm{a}$ - Going out at ance two nucleoli in one hepatocyte. b-Going out of nucleolus from binuclear hepatocyte.

c-Trinuclear hepatocyte. d-Going out of two nucleoli from binuclear hepatocyte.

they almost are not changed during all experiment $(90$ days). Almost fully disappearance of labels in many cells show that main mass of liver cells are renewed by 90 days, and, only single "longeviters" are kept without changes (without renovations or division) they keep primary content of labels. Thus, the analysis number of labeled hepatocytes' nuclei showed, that by 90 days the renewal of maximum hepatocytes' number occurs, and, only single ones and "longeviters" are kept without changes.

At histological analysis the state of hepatocytes' nuclei in healthy (control) rats was determined, that nucleolus' going out also takes place in these animals, but, rats' going out nucleolus was differ with little sizes and less dense nucleoloplasm. In all, the processes of going out and turning into new nucleus were exactly the same way, and, they repeated the stages of experimental rabbits (Fig. 4). Nucleolus' going out, as it was above mentioned, may be one of the ways of regeneratory processes of liver. In order to confirm the given presupposition it was solved to perform liver resection and monitoring dynamics of mitosis changing, and nucleolus' going out during this experiment. The results of taken studies showed that the most important data were taken at analysis of morphological picture for animals, being undergone to $25 \%$ liver resection. In early terms of experiment (3, 7 days) both the figures of mitotic division and nucleolus' going out were less (from 3 to 5\%o). But the number of nucleolus' going out was noticeable increased at 15 days approximately in 8-10 times (preliminary data), in comparison with the control, on the small area of vision the several 


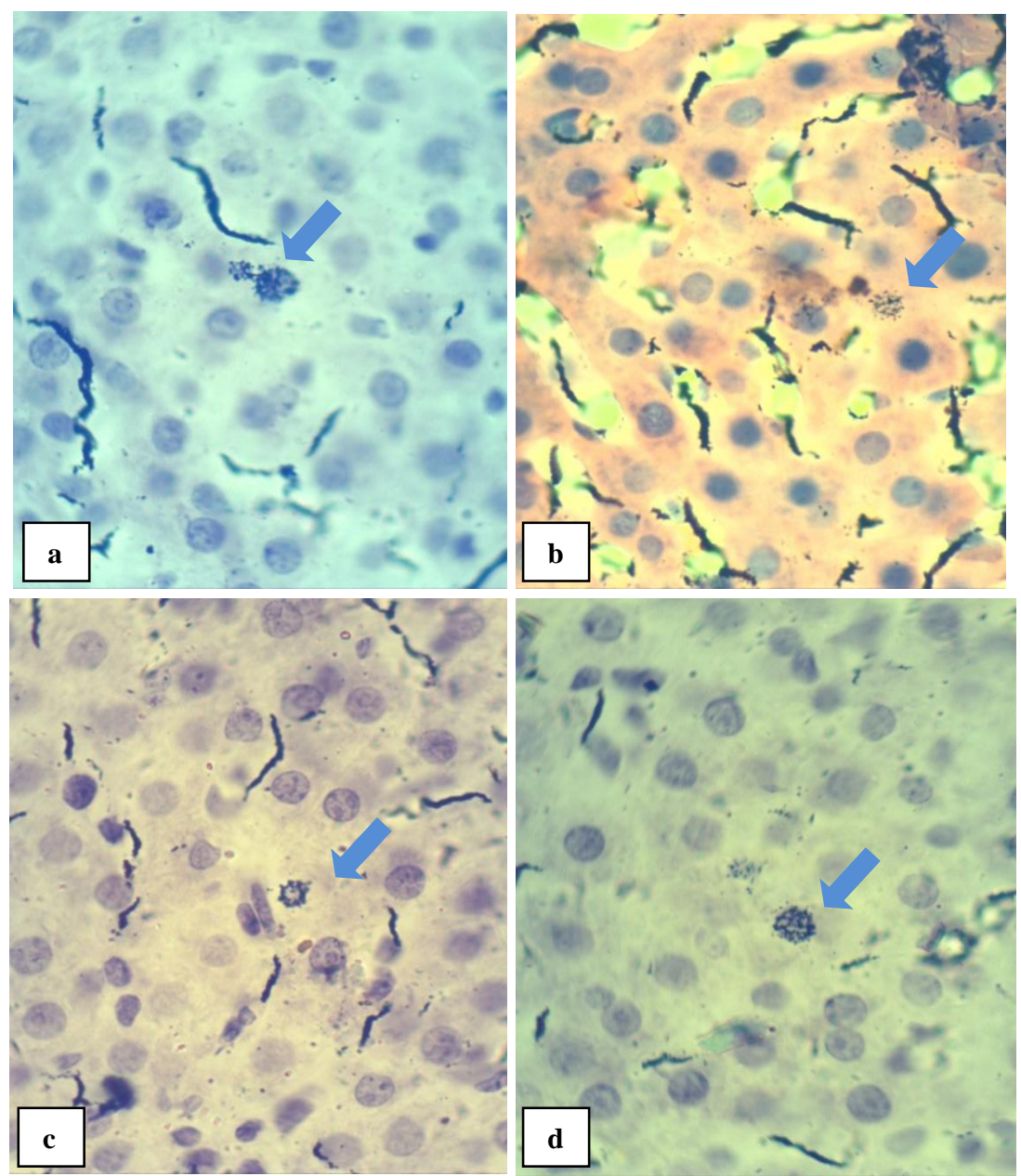

Fig. 3 Rat's liver. Introduction of labeled N3 is timidin. Colouring with hematoxilin-eosin.

a-Going out of nucleolus from hepatocyte's nucleus. (grains of timidin above nucleus and nucleolus) increase of label's number above the nucleolus. b-d—stages of nucleolus' development and it's conversion in nucleus.

dividing nucleoli were considerably less, approaching to norm. Thus, at resection of liver together with increasing, number of mitosis at 3, 5 days of experiment, the nucleolus' going out is considerably increase in liver cells with formation both multinuclear and young cells. The taken data witness on not only increase binuclear hepatocytes, but also on their participation in cellular renewal in liver, so in process of organ's regeneration.

\section{Nucleolus Regeneration at Liver Pathology}

Not coming in details on morphological picture of toxic hepatitis, causing introduction of heliotrin (they were described in many studies), we marked that in 40 days we got the picture of toxic hepatitis. At that, it was determined, that in parenchyma of liver, together with cellular necrosis foci, the less changed hepatocytes, mainly, being composed from uninuclear hepatocytes, occurred. The structure of many hepatocytes was considerably changed, their cytoplasm was vacuolized or undergone to fatty dystrophy, the nucleus' shapes were crooked, in some places the chromatin formed small accumulations, and, the most important, the structure of nucleolus was not clearly differentiated or it was revealed as little rude lumps in nucleolus (Fig. 5). In connection with considerable disorder of nucleolus' structure, their going out in hepatocytes was not found out. Nevertheless, in pathologically changed hepatocytes the figures of mitotic division, though the full valuability of those units had doubts. Disappearance 

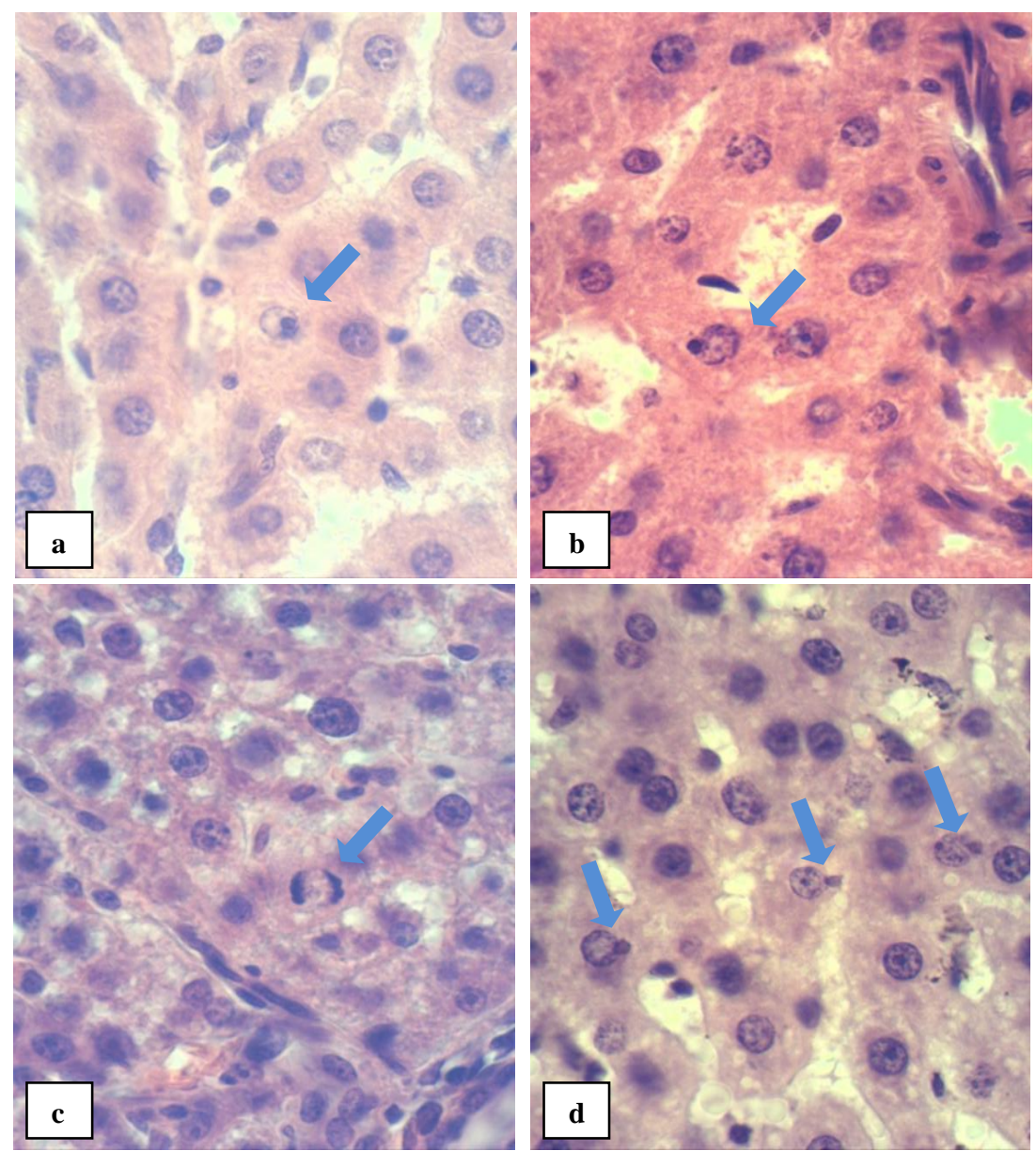

Fig. 4 Rat's liver.

a-Nucleolus' going out (control). b-d-Figures of mitosis and nucleolus' going out in hepatocytes after lever resection.

of bi-or and multinuclear cells apparently were connected with sharp reduce of polyploidy cells, those were the source of their formation at nucleolus' regeneration.

\section{Practical Significance of Given Phenomenon}

Till now, it was considered, that organs' regeneration, including liver, was provided with cellular division, compensatory hypertrophy, multinuclearity and polyploidy of cells. As it is known, in liver, all these moments are revealed in the highest level. But there are some moments those have not been guessing up to now. For example, at removing part of liver in rats the organ's mass was restored in 14-15 days, in dogs in 3 months, and, in man it in 6 months. Nevertheless, at all these mammals the mitotic index is increased only in 3, 7 days after operation, and, further it became the same, as in norm (2, 3 per 2500 cells). What processes are developed to full restoration of liver volume is unclear.

At study one of the new drugs, being administered for treatment patients with diseases of pulmonary ways, the drug " $\mathrm{N}$ " in the liver caused mass nucleolus' going out. For truth of this phenomenon display we show the picture, where on the small area of vision for periportal zone in liver lobule, the going out, at once, 6 nucleoli were found out (Fig. 6). As it was above mentioned, we said, that the nucleolus' going out leads not only to rejuvenation but to appearance of the new cells. Therefore, still not having approbated drug to the end, stimulated intensively the nucleolus' going out and promotes it's conversion into new nucleus. Thus, it can become to conclusion that nucleolus' going out is stimulated with drugs, and, such substances can be used 

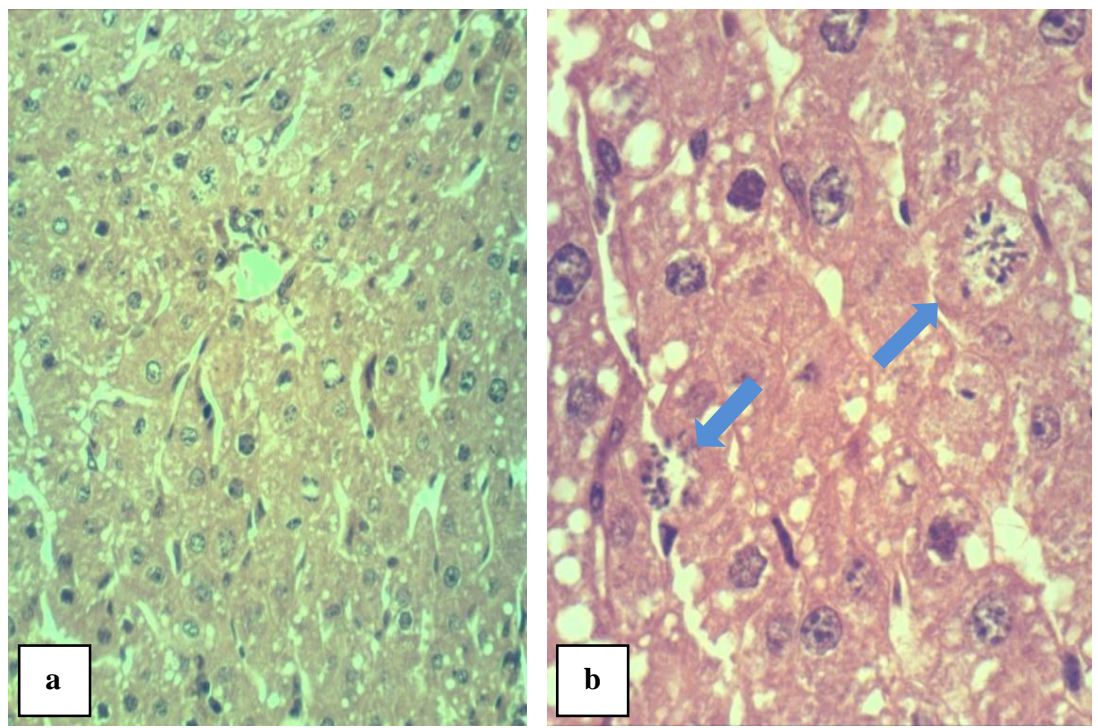

Fig. 5 Chronic toxic hepatitis. Rat's liver after introduction heliotrin.

a-Vacuole and fatty dystrophy and hepatocytes' destruction. $b$ - Changes of nucleus, disorder of nucleolus' structure and figures of mitotic hepatocytes division.
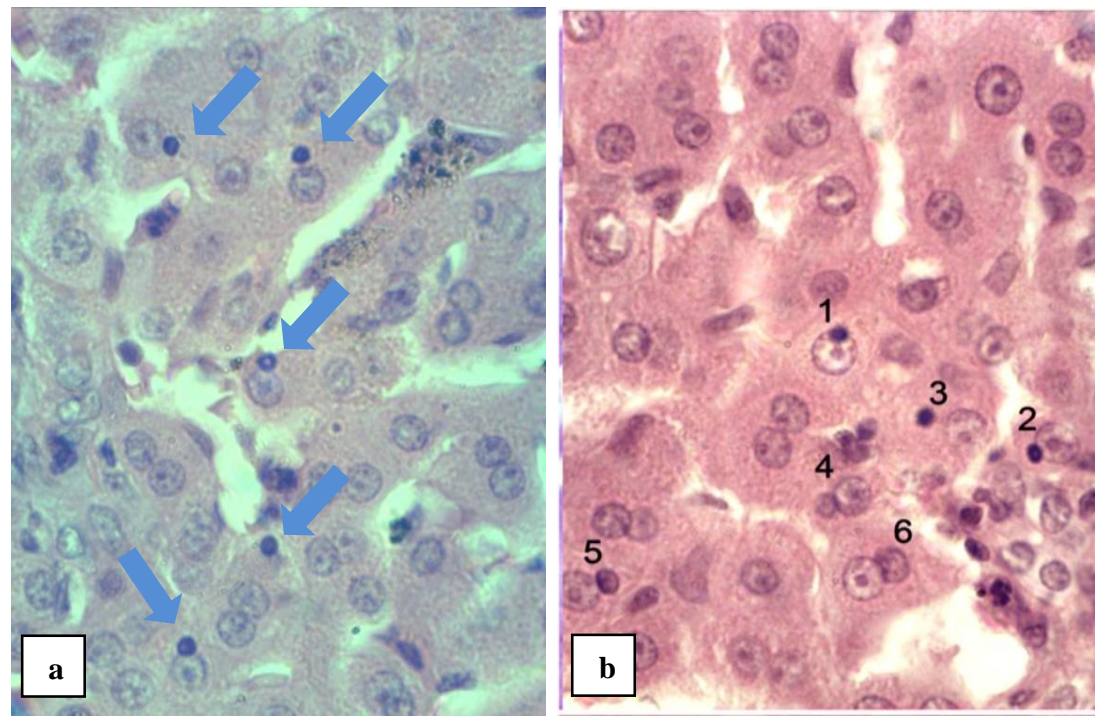

Fig. 6 Rabbit's liver. Introduction of drug.

a, b-Mass going out of nucleoli to perivenous and periportal zone of hepatic lobule. b — stages of nucleolus' going out from nucleus to conversion into new nucleus are seen (1-6).

at treatment liver pathology, including chronic hepatitis. The drug "N" can be wonderful means for treatment hepatitis $\mathrm{C}$ or initial stage of cirrhosis, that demands further studies. Thus, the new way of cellular rejunovation on the account of going out and reconstruction of seperated nucleolus. Being based on taken result, it can be come to construction, that in show renovating organs the absolute other way of renovating cells are existed (not mitotic division), but fully reconstruction of nuclear structure on the account of nucleolus' going out, and, its transformation into new nucleus with the following formation of bi-or and polynuclears or birth of "young" cell. At that, the main moment was, the occurring breakages in genetic material in the process of cell's vital activity, they are self-removed at repeated self-construction of RNA and DNA molecules. At that, apparently, only DNA molecule was formed (or either dispiralized or formed 
into RNA molecules like genetic material of viruses).

\section{Discussion}

The results of taken researches show that occurrences binuclear hepatocytes are not only connected with endomytosis [8,9] but due to going out nucleolus and its transformation into new nucleus [1]. Before going out, the nucleolus usually increases in volume, becomes dense and replaces to the nuclear membrane. Its volume increase is apparently associated with inforced synthesis of ribosomal genes by nucleolar organizers, and also with accumulation of DNA part around the nucleolus itself. The inforced synthesis of ribosomal genes with forming many nucleoli (amplification of RNA genes) were revealed in amphibian oocytes [2]. By these researchers' opinion the use ribosomal genes is typical only for sex cells, because in difference from somatic ones there was not polyploidy observed. In contrast to this, the mammalian and human hepatocytes are polyploid [9, 10]. Therefore, the increase of nucleolus in polyploidy liver cells, apparently, are caused not only increased synthesis of ribosomal genes, but also with DNA replication, the light optically expressed chromatin condensation around the nucleolus. These data are coincided with the researches $[3,7,8]$, who had identified that in nucleolus not only RNA (12-15\%), also DNA (2-10\%). Furthermore, the nucleus is the only structure of cell, having no membrane, so it has unclear contours inside. At penetrating nuclear membrane, it is obviously enveloped with nuclear membrane, and, therefore in cytoplasm it acquires smooth contours and spherical shape. After going out to cytoplasm, the nucleolus has internal reconstruction of its structure that is caused with clarification of karyoplasm and increase its volume, reaching the size of maternity one. At the end, the young nucleus takes place alongside with the maternity one. But in some cases, after going out of nucleolus, the maternal nucleus is undergone to serious changes, and, cytoplasm of such cell is clearly separated from surrounding cells. It can be supposed, that in some part of cases the maternity nucleus would be on the second part of cell, that cannot be, denied. Together with it was revealed that after nucleolus' going out, the maternity nucleus (except the cases when polynuclerars are formed) is swelled fist, then karyoplasm becomes light, the nuclear membrane changes it contours, and the nucleus looks like deformed. In some cases the maternity nucleus reduces in volume, fully dissolves and disappears. Nucleolus' going out and decomposition of old (maternity) nucleus , apparently, is accompanied with birth of new cell, when the nucleolus is transformed in absolute new nucleus and forms "young" cell together with surround cytoplasm. May be such mechanism of "rejuvenation" is in the base of cells' longevity that are slowly rejuvenated, may be in stable organs, including the liver. But here, is not everything clear how the nucleoli can form the valuable nucleus. Supposedly, there can be two main possible variants. At first, at nucleolus' going out, the part of DNA is also, caught together with nucleolus (supposedly, the diploid part from tetraploid that shows chromatin accumulation around the nucleolus), and, after going out to cytoplasm the fully untwisting of DNA spirals take place, in connection of that, the nucleoplasm is cleared up. At second, that may be less probable, after nucleolus' going out the DNA molecule is constructed on the base of RNA-molecule. Some suppositions for it are given the discovered back transcription, i.e. formation DNA molecule, at the result of transcription with RNA molecule in viruses. Thus, going out nucleoli from nucleus leads to double results. In the case of formation two, three and four nuclear hepatocytes, the old nuclei without significant changes are saved together with new young "nucleus". In some cases, after going out nucleolus, the old one is decomposed and disappears, giving way to young nucleus. Analyzing the whole process, it can be made, that the important part plays the nucleolus here, caring out the function of transfer nuclear material. Moreover, at result of this process, not only are bi- and 
polynuclears are formed, but also "young" cells formation occurs. It can be supposed that in this way the continuous renovation occur, or, in another way, "rejuvenation" of cells. Obviously, because of such periodic renovation of nuclear apparatus, the occurring genetic damages are self-removed at secondary DNA molecule construction. Thanks to it so long (long-living), the cells of our organism, without disturbing perform their main functions.

It should be mentioned, that going out nucleolus, except ours [1], is also described in alone study [11], where the authors state only the process of nucleolus going out to cytoplasm, in lower animals, in the cells of byssus gland of mussels molluscs. These researchers think, that separated nucleolus, in cytoplasm, participates is formation of secret. About participation of nucleolus in process of formation secret without going out into cytoplasm is indicated by other authors [1]. Nucleolus main components, going out, especially ribosomal subunits from nucleus to cytoplasm is widely recognized fact. Going out of larger fragments of nucleolus material, as it is indicated in the literature as "elimination of extrachromosomal material" is described in the oocytes of various insects, crustaceans, fish and amphibians [6, 12]. Thus, the results of taken researches show the more important part of nucleolus in process of cell's vital activity [13-17]. Besides the synthesis of ribosomal RNA, nucleoli are involved in formation of bi- and polynuclears, as well as in the processes of cell's renewal, by replacing older nuclei, through transformation of nucleolus into new nucleus occur. Nucleolus going out, apparently, is regular process, aimed to renovate of genetic material, i.e. self-elimination of breakdowns in the nuclear apparatus.

\section{Conclusions}

(1) In the liver the formation of bi- and polynuclears occurs due to going out the nucleolus and its transformation into new nucleus;

(2) In the liver as in slowly renovating organ, periodically performed the death of old and birth of new, one by going out the nucleolus and its transformation into new young nucleus is periodically carried out;

(3) In the liver nucleolonuclear transformation, periodically occurs due to self-destruction of breakdowns for genetic material;

(4) In liver, as in slow renewal organ, obviously on the account of nucleolus' going out periodically occurs the self-removement of appearing breakage for genetic material at formation of new nucleus;

(5) Preliminary count of labels show considerable dilution the labels number by 30 days, and, almost fully disappearance them by 90 days, and, it proves that DNA renoval of nucleus and cell on the whole at that period;

(6) At liver resection in regeneratory processes together with mitosis (3, 5 days) the hepatocytes' nucleoli participate, their going out increase in 15 day of experiment, therefore, in restoration the lost mass of organ nucleoli certainly participate, on the account of those, the formation both binuclear and multinuclear possible young cells, occur;

(7) At toxic damage of liver the number of polyploid cells is redused, that are the source of formation bi-and multinuclear hepatocytes on the account of nucleolus going out;

(8) The nucleolus' going out was stimulated with drugs, and, in connection with it occurred the necessity searching such substances, those could make therapeutic effect at disorder liver's regeneration.

\section{References}

[1] Sadriddinov, A. F. 2013. "The Role and Importance of Nucleolus in Formation of Binuclears in Liver Cells in the Coll." In proceedings of the Materials Intern Scientific and Practical, Krasnodar, 153-160.

[2] Boisvert, F. M., van-Koningsbruggen, S., Navascues, J., and Lamond, A. I. 2007. "The Multifunctional Nucleolus." Nat. Rev. Mol. Cell Biol. 8: 574-85.

[3] Hernandez-Verdun, D. 2006. "The Nucleolus: A Model for Organization of Nuclear Functions." Histochem Cell Biol. 126: 135-48. 
[4] Isaac, C., Marsh, K. L., Paznekas, W. A., Dixon, J., Dixon, M. J., Jabs, E. W., and Meier, U. T. 2000. "Characterization of the Nucleolar Gene Product, Treacle, in Treacher Collins Syndrome." Mol. Biol. Cell 11: 3061-71.

[5] Marciniak, R. A., Lombard, D. B., Johnson, F. B. and Guarente, L. 1998. "Nucleolar Localization of the Werner Syndrome Protein in Human Cells." Proc. Natl Acad. Sci. USA 95: 6887-92.

[6] Miller, Ol. Jr. 1981. "The Nucleolus, Chromosomas and Visualization of Genetic Activity." J. Cell. Biol. 9: 15-27.

[7] Scherl, A. Couté, Y., Déon, C., Callé, A., Kindbeiter, K., Sanchez, J. C., Greco, A., Hochstrasser, D., and Diaz, J. J. 2002. "Functional Proteomic Analysis of Human Nucleolus." Mol. Biol. Cell 13: 4100-9.

[8] Zatsepina, O.V. 1992. "Localization of DNA in the Mammalian Cell's Nucleoli." Cytology 34 (5): 34-39.

[9] Uuruvaeva, I. V. 1987. "Polyploidisein Mitosis and Polyploidy Biological Meaning in the Liver Cells." Cytology 12 (21): 1427-37.

[10] Kudryavtsev, B. N., Stein, G. I., and Tereshin, G. G. 1986. "Kinetics Analysis of Polyploidization of Parenchyma
Cells in Rat's Liver." Cytology 28 (8): 57-60.

[11] Kirpichnikova, U. S., and Levinson L.B. 1962. "Workshop on General Histology." Moscow p.236.

[12] Pederson, T. 1998. "The Multifunctional Nucleolus." Nucleic Acids Res. 26: 3871-6.

[13] Andersen, J. S., Lam, Y. W., Leung A. K., Ong, S. E, Lyon, C. E., Lamond, A. I., and Mann, M. 2005. "Nucleolar Proteome Dynamics." Nature 433:77-83.

[14] Brosh, R. M. Jr., Li, J. L., Kenny, M. K., Karow, J. K., Cooper, M. P., Kureekattil, R. P., Hickson, I. D., and Bohr, V. A. 2000. "Replication Protein A Physically Interacts with the Bloom's Syndrome Protein and Stimulates Its Helicase Activity." J. Biol. Chem. 275: 23500-8.

[15] Carmo-Fonseca, M., Mendes-Soares, L., and Campos, I. 2000. "To Be or Not to Be in the Nucleolus." Nat. Cell Biol. 2: 107-12.

[16] Mayer, C., Bierhoff, H., and Grummt, I. 2005. The Nucleolus as a Stress Sensor: JNK2 Inactivates the Transcription Factor TIF-IA and Down-Regulates RNA Synthesis. Genes Dev. 19: 933-41.

[17] Olson, M. O. J. 2004. "Sensing Cellular Stress: Another New Function for the Nucleolus Sci." STKE 224: 10. 